\title{
Pharmacoepidemiology of statins in East region of Kazakhstan
}

\section{Assem Makhatova, Raikhan Tuleutayeva, Aigerim Mussina, Andrey Gorbatenko}

Department of Pharmacology and Evidence-Based Medicine, Semey State Medical University, Semey, Republic of Kazakhstan

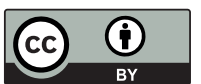

This work is licensed under a Creative Commons Attribution 4.0 International License

Received: 2018-01-12

Accepted: 2018-03-15

UDC: 616.1

\section{J Clin Med Kaz 2018;1(47):36-40}

Corresponding Author: Asem Makhatova, Department of Pharmacology and Evidence-Based Medicine, Semey State Medical University. Address: 40 G, Boztayev Street, ap. 241, Semey, Republic of Kazakhstan. Tel.: 87779860309,87471493429

E-mail: asem_ram@mail.ru

\section{Abstract}

Objective: To determine frequency, structure of antihyperholesterinemic therapy in the east region of Kazakhstan and compliance of the patients.

Material and Methods: The pharmacoepidemiological analysis was carried out on the basis of archival documents (medical history, outpatient cards) of 14 treatment and prevention institutions in Semey city of the East Kazakhstan region. A total of 3458 units of primary material were analyzed. The study included medical documentation of people with the diagnosis of ischemic heart disease, arterial hypertension, arterial atherosclerosis of lower limbs and other chronic diseases, as well as clinically healthy individuals with a study of the content of cholesterol in the blood. To determine adherence, the Moriski-Green test is used.

Results: It was revealed that the frequency of prescribing antihypercholesterolemic drugs (statins) in the conditions of Semey city is $80.7 \%$ of cases from the number of persons with clinical indications for their use. Atorvastatin $(89.7 \%)$ prevailed in the structure of antihypercholesterolemic therapy in patients with hypercholesterolemia and clinically manifested atherosclerosis. A low adherence to statin therapy has been revealed, reaching only $46.6 \%$ of the number of appointments and decreasing to $39.9 \%$ in individuals without clinical manifestations of atherosclerosis. The overall frequency of regular statin use in the group average, taking into account prescriptions and adherence, is $37.6 \%$ of the number of people with clinical indications and depends on the clinical diagnosis.

Conclusion: It is necessary to implement measures to correct the approaches of doctors to the appointment of antihypercholesterolemic therapy and work with patients aimed at increasing adherence to treatment.

Keywords: pharmacoepidemiology, statins, adherence

\section{РЕВМАТОИДТЫ АРТРИТТЫН СИРЕК АСҚЫНУЫ РЕТІНДЕ КРИОГЛОБУЛИНЕМИЯЛЫК ВАСКУЛИТ: КЛИНИКАЛЫҚ ЖАҒДАЙ. \\ Махатова Ә.Р., Тулеутаева Р.Е., Мусина Ә.Е., Горбатенко А.Е.}

Фармакология және дәлелді медицина кафедрасы, Семей қаласының мемлекеттік медицина университеті, Семей, Қазақстан Республикасы

\section{ТҰЖЫРЫМДАМА}

Мақсаты: Қазақстанның шығыс өңіріндегі антигиперхолестеринемиялық емнің жиілігін, құрамын және науқастың бейімділік көрсеткіштерін бақылау анықтау.

Әдістері: Фармакоэпидемиологиялық талдау Шығыс-Қазақстан облысындағы 14 емдеу-алдын алу мекемелерінің мұрағаттық құжаттарының (ауру тарихтары, амбулаторлы карталар) негізінде жасалған. Барлығы 3458 бірлік бастапқы заттар талданды. Талдауға ЖИА, артериалды гипертензиясы, аяқтың артериясының атеросклерозы диагнозы және басқа да созылмалы аурулары бар және де қанындағы холестерин құрамы зерттелген клиникалық дені сау адамдардың медициналық құжаттары алынды. Бейімділікті анықтау үшін Мориски-Грина тесті қолданылды.

Нәтижесі: Семей қ. жағдайында антигиперхолестеринемиялық препараттарды (статиндерді) тағайындау жиілігі оларды қолдануға клиникалық көрсеткіштерімен адамдар санының 80,7\% құрайтындығы айқындалды. Зерттеу кезінде гиперхолестеринемиялар мен клиникалық манифестирленген атеросклерозы бар науқастардың антигиперхолестеринемия емінің құрылымында аторвастатин (89,7\%) басым болды. Тағайындау саны 46,6\% жететін және атеросклероздың клиникалық көрінісінсіз адамдарда 39,9\% дейін азаятын статиндермен емге төмен бейімділік анықталды. Топ бойынша статиндерді қолданудың жалпы жиілігі тағайындау мен бейімділікті есепке алғанда клиникалық көріністері бар адамдардың 37,6\% құрайды және клиникалық диагнозға байланысты.

қорытынды: Емге бейімділікті жоғарлатуға бағытталған антигиперхолестеринемиялық емді тағайындауға келу және науқастармен жұмысты түзету бойынша дәрігерлердің іс-шараларды жүзеге асыруы қажет.

Негізгі сөздер: фрармакоэпидемиология, статиндер, бейімділік 


\section{PЕЗЮME}

Цель: определить частоту, структуру антигиперхолестеринемической терапии в восточном регионе Казахстана и показатели приверженности пациентов.

Материалы и методы: Фармакоэпидемиологический анализ осуществлен на материале архивных документов (истории болезни, амбулаторные карты) 14 лечебно-профилактических учреждений г.Семей Восточно-Казахстанской области. Всего проанализировано 3458 единиц первичного материала. В исследование включалась медицинская документация лиц с наличием диагноза ишемической болезни сердца, артериальной гипертензии, атеросклероза артерий нижних конечностей и других хронических заболеваний, а также клинически здоровых лиц с осуществленным исследованием содержания в крови холестерина. Для определения приверженности использован тест Мориски-Грина.

Результаты: Выявлено, что частота назначения антигиперхолестеринемических препаратов (статинов) в условиях г.Семей составляет 80,7\% случаев от числа лиц с клиническими показаниями к их применению. В структуре антигиперхолестеринемической терапии пациентов с гиперхолестеринемиями и клинически манифестированным атеросклерозом в период исследования преобладал аторвастатин (89,7\%). Выявлена низкая приверженность к терапии статинами, достигающая лишь 46,6\% от числа назначений и снижающаяся до 39,9\% у лиц без клинических проявлений атеросклероза. Общая частота регулярного применения статинов в среднем по группе с учетом назначений и приверженности составляет 37,6\% от числа лиц с клиническими показаниями и зависит от клинического диагноза.

Заключение: Требуется осуществление мероприятий по коррекции подходов врачей к назначению антигиперхолестеринемической терапии и работе с пациентами, направленных на повышение приверженности к лечению.

Ключевые слова: фрармакоэпидемиология, статины, приверженность

\section{Введение}

В современных условиях антигиперхолестеринемические препараты входят в число наиболее часто применяемых в клинической практике [1-4]. Согласно существующим рекомендациям, они назначаются не только пациентам с клинически манифестированными проявлениями атеросклероза магистральных артерий, но и при наличии повышенного уровня холестериналюбогогенеза и других факторов риска ишемической болезни сердца (ИБС) $[5,6]$. Другой особенностью антигиперхолестеринемических препаратов является необходимость их применения длительными курсами, зачастую пожизненно. В результате каждый пациент получает большое количество препарата, что вносит значительный вклад в общую стоимость лечения и экономическое бремя заболевания $[7,8]$.

Целесообразность назначения антигиперхолестеринемических препаратов вообще и относящихся к различным фармакологическим группам в частности, у каждого конкретного больного должна определяться индивидуально, исходя из особенностей его метаболизма, характеристик патологического процесса (рассматриваемых в совокупности как уровень нострифицированного сердечно-сосудистого риска), а также взаимодействия организма больного и предполагаемого к назначению препарата $[9,10]$.

В последнем случае существенный интерес представляет возможность снижения эффективности и развития побочных эффектов антигиперхолестеринемической терапии, связанных с генетическими особенностями. Наибольший риск в этом отношении представляют наиболее распространенные в клинической практике препараты класса статинов, в частности аторвастатин $[11,12]$.

В связи с этим большую актуальность приобретает вопрос структуры антигиперхолестеринемической терапии (АГХТ), осуществляемой в определенных популяциях, т.е. фармакоэпидемиологии статинов.

Целью исследования является определить частоту, структуру антигиперхолестеринемической терапии в восточном регионе Казахстана и показатели приверженности пациентов

\section{Материалы и методы}

Фармакоэпидемиологический анализ осуществлен на материале архивных документов (истории болезни, амбулаторные карты) 14 лечебно-профилактических учреждений г.Семей, в т.ч. 2 стационаров и 12 учреждений амбулаторно-поликлинической службы. Всего за период 2013-2017 гг. проанализировано 3458 единиц первичного материала. В исследование включалась медицинская документация лиц с наличием диагноза ИБС, артериальной гипертензии, атеросклероза артерий нижних конечностей и других хронических заболеваний, а также клинически здоровых лиц с наличием показаний и осуществленным исследованием содержания в крови холестерина.

При этом, согласно рекомендациям EAS/ESC 2016, показания к назначению АГХТ дифференцировали в зависимости от степени сердечно-сосудистого риска. Во всех случаях постулировалась необходимость снижения содержания холестерина липопротеидов низкой плотности менее 2,6 мМ/л, при наличии очень высокого риска - менее 1,8 мМ/л [13]. Наличие показаний являлось главным критерием включения в исследование. Bсе данные были распределены в зависимости от наличия следующих состояний: гиперхолестеринемия с ИБС; гиперхолестеринемия с атеросклеротическими поражениями церебральных артерий (ишемическая болезнь мозга - ИБМ); гиперхолестеринемия с атеросклерозом артерий нижних конечностей; гиперхолестеринемия c клиническими проявлениями атеросклеротического процесса других локализаций; гиперхолестеринемия без клинических проявлений атеросклероза (Таблица 1). Наличие каждого предшествующего состояния исключало включение пациента в последующую категорию.

Учитывались данные о назначении АГХТ, рекомендуемый препарат, продолжительность первичного и повторных курсов АГХТ, наличие контрольного исследования содержания холестерина в крови и липопротеидных фракций, сведения об исполнении врачебных назначений в случае стационарного лечения, сведения об источнике препаратов в случае их наличия.

Для оценки приверженности больных к АГХТ осуществлено анкетирование 755 пациентов с гиперхолестеринемией. Большинство $(85,8 \%)$ из них имели клинические признаки поражения магистральных сосудов (ИБС, в том числе с эпизодами острого коронарного синдрома, атеросклероз артерий нижних конечностей, почек, цереброваскулярная недостаточность атеросклеротического 


\begin{tabular}{|c|c|c|c|c|c|}
\hline \multirow[t]{2}{*}{ Группа } & \multicolumn{2}{|c|}{ Число пациентов } & \multicolumn{2}{|l|}{ Пол (М/Ж) } & \multirow{2}{*}{$\begin{array}{l}\text { Средний } \\
\text { возраст, лет }\end{array}$} \\
\hline & абс. & $\%$ & абс. & $\%$ & \\
\hline Гиперхолестеринемия с ИБС & 1420 & 41,1 & $992 / 428$ & $69,9 / 30,1$ & $57,2 \pm 3,5$ \\
\hline Гиперхолестеринемия с ИБМ & 436 & 12,6 & $250 / 186$ & $57,3 / 42,7$ & $56,9 \pm 4,1$ \\
\hline $\begin{array}{l}\text { Гиперхолестеринемия с атеросклерозом артерий нижних } \\
\text { конечностей }\end{array}$ & 378 & 10,9 & $263 / 115$ & $69,6 / 30,4$ & $55,2 \pm 4,3$ \\
\hline $\begin{array}{l}\text { Гиперхолестеринемия с проявлениями атеросклеротического } \\
\text { процесса других локализаций }\end{array}$ & 165 & 4,8 & $103 / 62$ & $62,4 / 37,6$ & $55,7 \pm 3,9$ \\
\hline Гиперхолестеринемия без клинических проявлений & 1059 & 30,6 & $585 / 474$ & $55,2 / 44,8$ & $54,3 \pm 2,8$ \\
\hline Всего & 3458 & 100 & $2193 / 1265$ & $63,4 / 36,6$ & $56,0 \pm 2,6$ \\
\hline
\end{tabular}

генеза, в том числе с эпизодами острых нарушений мозгового кровообращения). Анкетирование проводилось с использованием методики Мориски-Грина.

Статистический анализ результатов осуществлялся путем сравнения частотных показателей с использованием критерия $\chi 2$ Пирсона.

\section{Результаты}

Данные, характеризующие частоту назначения АГХТ статинами в зависимости от клинического состояния, представлены на Рисунке 1.

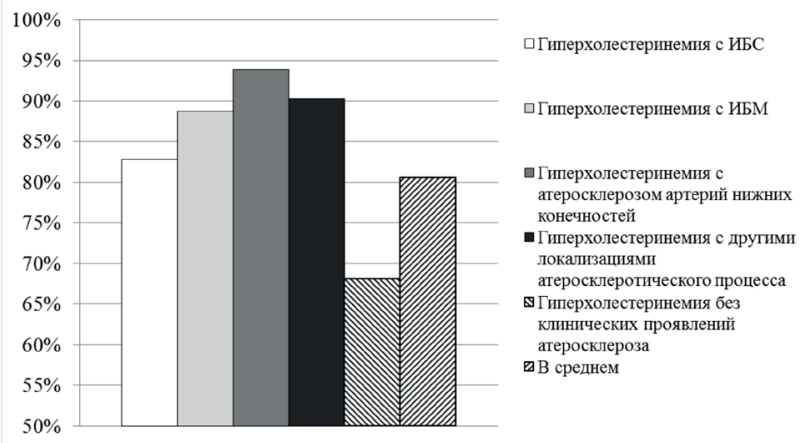

Рисунок 1 - Процент пациентов с назначенной терапией статинами

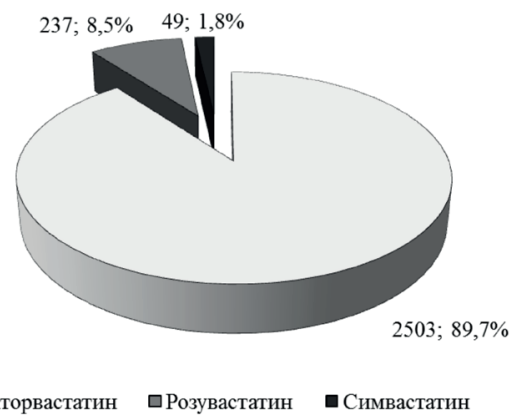

Рисунок 2 - Структура назначенной терапии статинами

В среднем по всей группе опрошенных процент приверженности составил 46,6\%. Наиболее высоким он был у больных с атеросклерозом артерий нижних конечностей и другими локализациями (61,1\% и $62,4 \%$ соответственно) Эти показатели имели значимое превышение над средним по группе уровнем $(\chi 2=26,44, \mathrm{p}<0,001$ и $\chi 2=14,10, \mathrm{p}=0,016) . \mathrm{K}$ сожалению, существенно более низкими были показатели у
В среднем по всей группе включенных в исследование процент назначения статинов был довольно высоким 80,7\%. При этом наибольшие показатели характеризовали подгруппы пациентов с атеросклерозом нижних конечностей - 93,9\% (различия со средним показателем значимы, $\chi 2=40,55, \quad \mathrm{p}<0,001)$, другими локализациями клинически манифестированного атеросклероза - 90,3\% $(\chi 2=9,56, p=0,017)$ и ишемической болезнью мозга $-88,8 \%$. В то же время, у лиц без клинически манифестированного атеросклероза частота назначения статинов была значительно меньшей и составила только $68,2 \%(\chi 2=72,89$, $\mathrm{p}<0,001)$.

Следует заметить, что другие варианты антигиперхолестеринемической терапии (назначение фибратов) осуществлялись лишь в единичных случаях, число которых может считаться пренебрежимо малым.

На Рисунке 2 представлена структура назначаемых статинов. Использованы только три препарата аторвастатин, розувастатин и симвастатин, причем с подавляющим преобладанием первого, составившего 89,7\% всех назначений.

На Рисунке 3 представлены данные о приверженности больных терапии статинами в соответствии с результатами теста Мориски-Грина, распределенные в зависимости от клинического состояния.

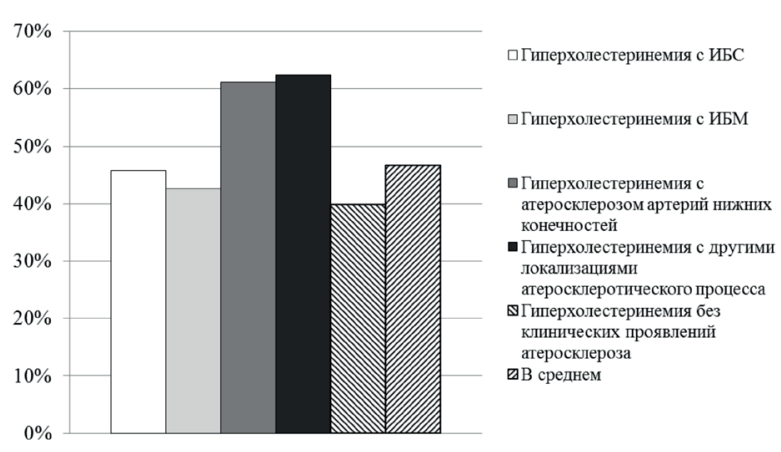

Рисунок 3 -Процент приверженности пациентов к назначенной терапии статинами

пациентов с ИБС $(45,7 \%)$ и ИБМ (42,6\%), которые не имели значимых различий со средним уровнем приверженности.

Как и следовало ожидать, самым низким оказался уровень приверженности у лиц без клинических проявлений атеросклероза (39,9\%), хотя значимых различий со средним уровнем не было выявлено и в данном случае. 
При оценке реального уровня терапии гиперхолестеринемии мы использовали данные о частоте назначения статинов и приверженности одновременно (Рисунок 4).

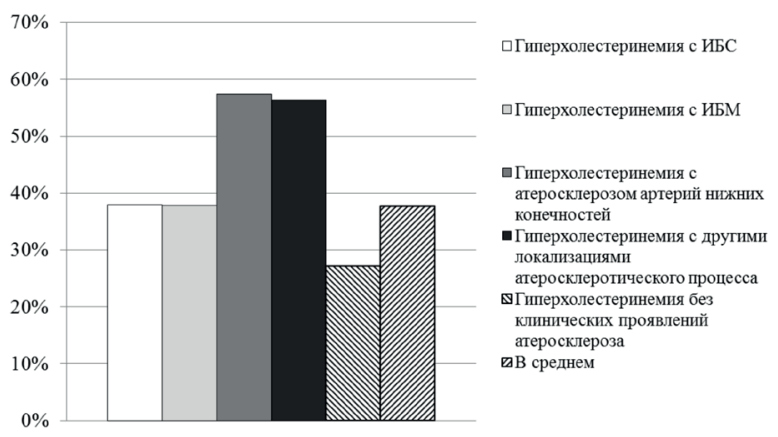

Рисунок 4 - Процент пациентов, регулярно принимающих статины от числа нуждающихся в АГХТ

В среднем по всей группе частота применения статинов относительно численности лиц с имеющимися показаниями составила только $37,6 \%$.

Только в двух подгруппах, причем самых немногочисленных, показатель осуществления терапии превышал 50\% - у пациентов с атеросклерозом артерий нижних конечностей $(57,4 \%$; при сравнении со средним показателем $\chi 2=55,78, \mathrm{p}<0,001)$ и другими локализациями атеросклеротических поражений $(56,4 \% ; \quad \chi 2=23,37$, $\mathrm{p}=0,002)$. У пациентов с ИБС и ИБМ частота проводимой терапии статинами оказалась практически равной и соответствовала среднему уровню (37,9\% и 37,8\%). Еще более низким оказался процент профилактики атеросклероза у лиц с повышенным содержанием холестерина в крови без клинических проявлений (только $27,2 \% ; \chi 2=38,66, \mathrm{p}<0,001$ ).

\section{Обсуждение результатов}

Антигиперхолестеринемическая терапия относится к числу подходов к первичной и вторичной профилактике в клинике внутренних болезней, имеющих доказанную эффективность [14]. Применение препаратов из класса статинов остается основным подходом к этому варианту лечения и профилактики сердечно-сосудистых заболеваний $[15,16]$. В некоторых странах терапии статинами подвергается до 15-20\% взрослого населения [17].

Кроме непосредственного воздействия на содержание холестерина и баланс липопротеидных фракций [18], статины обладают комплексом т.н. плейотропных эффектов, позитивно воздействующих на механизмы патогенеза сердечно-сосудистых и других заболеваний [19-21]. Однако имеются и данные о негативных эффектах препаратов, вплоть до индукции развития сахарного диабета [22,23].

Поэтому терапия статинами во всех аспектах является предметом тщательного изучения.

Предметом нашего исследования являлся вопрос адекватности терапии статинами в плане ее назначения в соответствии с клиническими показаниями и приверженности пациентов. Следует заметить, что все полученные результаты были основаны на данных анкетных опросов и анализа медицинской документации. Это можно рассматривать как недостаток исследования, поскольку результаты, особенно в отношении опроса по приверженности, не могли быть подвергнуты проверке.
Тем не менее, даже исходя из полученных данных, можно отметить очень низкую в сравнении с показаниями частоту приема препаратов. Общий уровень в среднем по группе с учетом назначений и приверженности составил лишь 37,6\%. Это значит, что лишь 1 из 3 пациентов с определенными клиническими показаниями к применению статинов действительно регулярно принимает препарат из данного класса в соответствии с назначениями. Этот уровень в сравнении с результатами зарубежных исследований (представляющих частоту приверженности в пределах 4070\%) необходимо признать достаточно низким [24-26].

Кроме того, наиболее часто применяемым препаратом остается аторвастатин, причем чаще всего в форме генериков различного производства, эффективность которых может быть ниже, чем показана в клинических исследованиях [27].

Таким образом, полученные данные позволяют предполагать заведомо недостаточную эффективность АГХТ в популяции г.Семей. Врачи назначают главным образом наименее эффективный препарат данного класса, обладающий наибольшим риском развития побочных эффектов. Пациенты имеют низкую приверженность к его приему, причем в наибольшей степени это проявляется в группе лиц без клинических проявлений атеросклероза, где адекватная его профилактика могла бы позволить добиться отсутствия сосудистых осложнений любых локализаций. Несколько большая приверженность к терапии у больных с ИБС и ИБМ также не достигает адекватных величин регулярный прием препаратов осуществляется менее чем в $50 \%$ случаев.

\section{Заключение}

1. Антигиперхолестеринемические препараты (статины) в условиях г.Семей назначаются в 80,7\% случаев от числа лиц с клиническими показаниями к их применению.

2. В структуре антигиперхолестеринемической терапии пациентов с гиперхолестеринемиями и клинически манифестированным атеросклерозом преобладает аторвастатин $(89,7 \%)$.

3. Наблюдается низкая приверженность к терапии статинами, достигающая лишь $46,6 \%$ от числа назначений и снижающаяся до $39,9 \%$ у лиц без клинических проявлений атеросклероза.

4. Общая частота регулярного применения статинов в среднем по группе с учетом назначений и приверженности составляет $37,6 \%$ от числа лиц с клиническими показаниями.

Disclosures: There is no conflict of interest for all authors. 


\section{References}

1. Ponomaryova A.I., Kompaniets O.G., Linchak R.M., Agafonova G.A. Farmakojepidemiologija statinov u pacientov s gipertonicheskoj bolezn'ju i dislipidemiej (Statins pharmacoepidemiology in patients with hypertonic disease an dyslipidemia). Kardiologija. 2015. 10:25-31.

2. Chou R, Dana T, Blazina I. et al. Statins for Prevention of Cardiovascular Disease in Adults: Evidence Report and Systematic Review for the US Preventive Services Task Force. JAMA. 2016. 15;316(19):2008-2024.

3. Doyle MN, Bhimji SS. Statin Medications. StatPearls [Internet]. Treasure Island (FL): StatPearls Publishing. 2017.

4. Miller PE, Martin SS. Approach to Statin Use in 2016: an Update. Curr Atheroscler Rep. 2016; 18(5):20.

5. Kazi DS, Penko JM, Bibbins-Domingo K. Statins for Primary Prevention of Cardiovascular Disease: Review of Evidence and Recommendations for Clinical Practice. Med Clin North Am. 2017; 101(4):689-699.

6. Davies JT, Delfino SF, Feinberg CE. et al. Current and Emerging Uses of Statins in Clinical Therapeutics: A Review. Lipid Insights. 2016; 9: 13-29.

7. Simoens S, Sinnaeve PR. Generic atorvastatin, the Belgian statin market and the cost-effectiveness of statin therapy. Cardiovasc Drugs Ther. 2013; 27(1):49-60.

8. Lin I, Sung J, Sanchez RJ. et al. Patterns of Statin Use in a Real-World Population of Patients at High Cardiovascular Risk. $J$ Manag Care Spec Pharm; 22(6):685-698.

9. Anderson TJ, Grégoire J, Pearson GJ. et al. 2016 Canadian Cardiovascular Society Guidelines for the Management of Dyslipidemia for the Prevention of Cardiovascular Disease in the Adult. Can J Cardiol. 2016; 32(11):1263-1282.

10. Wadhera RK, Steen DL, Khan I. et al. A review of low-density lipoprotein cholesterol, treatment strategies, and its impact on cardiovascular disease morbidity and mortality. J Clin Lipidol. 2016; 10(3):472-89.

11. Bitto A, Pallio G, Messina S. et al. Genomic Variations Affecting Biological Effects of Statins. Curr Drug Metab. 2016; 17(6):566-72.

12. Swerdlow DI, Preiss D. Genetic insights into statin-associated diabetes risk. Curr Opin Lipidol. 2016; 27(2):125-30.

13. 2016 EAS/ESC Guidelines for the Management of Dyslipidaemias. Eur. Heart J. 2016; 37:2999-3058.

14. Nayor M, Vasan RS. Recent Update to the US Cholesterol Treatment Guidelines: A Comparison With International Guidelines. Circulation. 2016; 133(18):1795-806.

15. Toth PP. Novel Therapies for Low-Density Lipoprotein Cholesterol Reduction. Am J Cardiol. 2016; 118(6):19A-32A.

16. Retornaz F, Beliard S, Gremeaux E. et al. Statin and cardiovascular diseases after 75 years. Rev Med Interne. 2016; 37(9):625-31.

17. Li X, Stürmer T, Brookhart MA. Evidence of sample use among new users of statins: implications for pharmacoepidemiology. Med Care. 2014; 52(9):773-80.

18. 18. Graham IM, Catapano AL, Wong ND. Current guidelines on prevention with a focus on dyslipidemias. Cardiovasc Diagn Ther. 2017; 7(1):4-10.

19. Sehra D, Sehra S, Sehra ST. Cardiovascular pleiotropic effects of statins and new onset diabetes: is there a common link: do we need to evaluate the role of KATP channels? Expert Opin Drug Saf. 2017; 16(7):823-831.

20. Bedi O, Dhawan V, Sharma PL, Kumar P. Pleiotropic effects of statins: new therapeutic targets in drug design. Naunyn Schmiedebergs Arch Pharmacol. 2016; 389(7):695-712.

21. Babcook MA, Joshi A, Montellano JA, Shankar E, Gupta S. Statin Use in Prostate Cancer: An Update. Nutr Metab Insights. 2016; 9:43-50.

22. Oscanoa Espinoza TJ, Paredes-Pérez N, Lizaraso-Soto F. Safety of statins. Rev Fac Cien Med Univ Nac Cordoba. 2016; 73(4):263-278.

23. Laakso M, Kuusisto J. Diabetes Secondary to Treatment with Statins. Curr Diab Rep. 2017; 17(2):10.

24. 24. Bosworth HB, Brown JN, Danus S. et al. Evaluation of a packaging approach to improve cholesterol medication adherence. Am J Manag Care. 2017; 23(9):280-286.

25. Ofori-Asenso R, Jakhu A, Zomer E. et al. Adherence and Persistence among Statin Users aged 65 years and over: A Systematic Review and Meta-analysis. J Gerontol A Biol Sci Med Sci. 2017.

26. Colantonio LD, Huang L, Monda KL, et al. Adherence to High-Intensity Statins Following a Myocardial Infarction Hospitalization Among Medicare Beneficiaries. JAMA Cardiol. 2017; 2(8):890-895.

27. Tran YB, Frial T, Miller PS. Statin's cost-effectiveness: a Canadian analysis of commonly prescribed generic and brand name statins. Can J Clin Pharmacol. 2007; 14(2):205-14.

How to cite this article: Assem Makhatova, Raikhan Tuleutayeva, Aigerim Mussina, Andrey Gorbatenko. Pharmacoepidemiology of statins in East region of Kazakhstan [in Russian]. J Clin Med Kaz. 2018; 1(47):36-40 